\title{
LA REVOLUCIÓN INHALLABLE
}

\author{
Carlos Peña \\ Universidad Diego Portales, Chile
}

\begin{abstract}
Resumen: Este artículo explora algunas de las causas que subyacen a los sucesos de octubre en Chile. Sugiere que en el debate que siguió inmediatamente a esos hechos se puso más énfasis en la adscripción de significados normativos que en el examen de los factores que los hicieron posible. Una revisión de la literatura ayudaría a indagar en estos últimos. Esa literatura — desde la sociología clásica al examen de los nuevos movimientos sociales a partir de los años ochenta- mostraría que, en términos generales, las sociedades que experimentan rápidos procesos de modernización configuran una inconsistencia entre la racionalización técnica indispensable para promover el bienestar con la subjetivación que inunda el mundo de la vida. Ello explicaría que la protesta no sea solo reivindicativa o ideológica, y en cambio se exprese con medios altamente emotivos y escénicos, que semejan un esfuerzo por configurar la gramática de las formas de vida. Esto dibuja una condición ambivalente en la sociedad chilena que plantea un particular desafío a los ideales normativos que promueve la política.

PALABRAS ClAVE: modernización, malestar, crisis, subjetividad, subjetivación
\end{abstract}

RECIBIDO: marzo 2020 / ACEPTADO: mayo 2020

Carlos Peña es abogado, cursó estudios de posgrado en sociología y es doctor en filosofía por la Universidad de Chile. Profesor asociado de la Universidad de Chile y rector de la Universidad Diego Portales (Santiago, Chile). Sus últimas publicaciones son Lo que el dinero sí puede comprar (Santiago, Madrid, 2017); Por qué importa la filosofía (Santiago, 2018); El tiempo de la memoria (Santiago, 2019); Pensar el malestar (Santiago, 2020), todos por el sello Taurus (Penguin Random House). Dirección: Universidad Diego Portales, Manuel Rodríguez 450, Santiago, Chile, CP 8320000. Email: carlos.pena@udp.cl. 


\section{THE ELUSIVE REVOLUTION}

ABSTRACT: This article explores some of the causes behind the events of October in Chile. It suggests that in the debate that immediately followed those events, more emphasis was placed on ascribing normative meanings to those events than on examining their causes. A review of the literature would help to explore the latter. Such literature -from classical sociology to the examination of new social movements- would show that, in general terms, societies undergoing rapid modernization processes configure an inconsistency between the technical rationalization indispensable to promote welfare with the subjectivation that floods the world of life. This would explain why protest is not only vindictive or ideological and is expressed, instead, with highly emotional and scenic means until it configures an effort to draw the grammar of life forms. All this configures, he concludes, an ambivalent condition in Chilean society that poses a particular challenge to the normative ideals promoted by politics.

KEYwORDs: modernization, malaise, crisis, subjectivity, subjectivation

ReCEIVED: March 2020 / ACCEPTED: May 2020

\section{INTRODUCCIÓN}

- n 1968, Raymond Aron publicó La Revolution Introuvable. Re- flexions sur les evenements de Mai. El texto reunía un conjunto de artículos periodísticos escritos a la par que ocurrían los hechos que comentaba, seguidos de una entrevista. Lo que entonces había ocurrido, decía Aron (1968a), era el producto de las contradicciones de la sociedad industrial, un síntoma de ella más que un cambio revolucionario. La revolución no aparecería, predijo, por ninguna parte.

Treinta años después, Peter Wagner (1994) estuvo de acuerdo con él y sugirió que los acontecimientos de mayo del 68, y otros que le siguieron, fueron síntomas de una crisis de la modernidad organizada. La modernidad organizada, explicó, había sido el esfuerzo por incluir a los individuos en regulaciones colectivas en la esfera del trabajo y la distribución de beneficios. En la década de 1970, las nuevas generaciones pusieron en duda esos arreglos recuperando la ambivalencia de la modernidad. Y, a pesar de lo que en su momento se creyó, no hubo una revolución: 
Se rumoreaba en Francia que el presidente de la república planeaba huir del país, al modo como lo había intentado el rey en la época de la revolución. En Estados Unidos, la Guardia Nacional ocupó los campus universitarios. Algunos estudiantes cayeron abatidos por las balas. En Italia había quienes consideraban que el país se hallaba al borde de una revolución social y algunos grupos de la clase política preparaban en secreto un golpe de estado que abriera la puerta a una dictadura militar para poner fin a las agitaciones. Desde la perspectiva actual, todas aquellas reacciones producen la impresión de haber sido extremadamente desorbitadas. (Wagner 1994, 141-142)

¿Se dirá lo mismo, luego de algún tiempo, de las reacciones que suscitaron los acontecimientos de octubre en Chile? ¿Nos parecerán desorbitadas?

Las líneas que siguen sugieren que sí. Ellas exploran la literatura para mostrar que el fenómeno de octubre en Chile no es raro ni sorprendente en una sociedad que ha experimentado un rápido proceso de modernización (para una exposición más pormenorizada de lo que sigue, Peña 2020). La desigualdad, se sugiere más adelante, hiere más en una sociedad cuyo bienestar se incrementa y ello sumado a la individuación, al impulso por editar la vida al compás de la propia subjetividad, le confieren a la protesta de octubre esos rasgos de teatralidad, resistencia a la autoridad y protagonismo juvenil que no suelen presentarse en los tradicionales movimientos reivindicativos.

Desgraciadamente, el entusiasmo por adscribir al fenómeno un cierto contenido normativo - algo que es propio de la lucha política-, ensombreció esos rasgos que lo hacen peculiar y digno de análisis.

En la siguiente parte del artículo se examina esa confusión entre la explicación del fenómeno y su justificación ex post, así como el papel que cumple la desigualdad en él (2). Sobre esa base se identifican dos problemas que luego se intenta dilucidar: ¿por qué una sociedad que ha disminuido la desigualdad experimenta, sin embargo, una vivencia de la desigualdad cada vez más aguda? ¿A qué se debería el particular rasgo de esa protesta, su cariz a veces dramático, la heterogeneidad de sus mensajes y su carácter poco reivindicativo? Una revisión de la literatura 
permite encontrar en ella hipótesis de largo alcance para responder, en términos generales, esas preguntas.

A la primera se dedican las secciones tres y cuatro, que recuerdan la noción de Sen de objetividad posicional y la de anomia o desinstitucionalización que se encuentra en la obra de Durkheim o de Gehlen. De la segunda tratan las secciones quinta y sexta, donde se recuerdan algunas investigaciones que subrayan de qué forma los movimientos sociales expresan un desajuste entre la racionalidad de la modernización y la subjetividad de los individuos. La sección sexta describe además la crisis de legitimidad que sería el resultado de todo lo anterior. El texto finaliza explorando el contenido normativo que subyace a esos fenómenos (7) y con una conclusión general (8).

\section{EL SIMPLISMO DEL DEBATE Y LA VIVENCIA DE LA DESIGUALDAD}

Ante todo, cabe llamar la atención acerca del simplismo que inundó los medios de comunicación y la esfera pública en torno a octubre y los meses siguientes de 2019. Ese simplismo consistió en atribuir los hechos de ese tiempo - la violencia, seguida de una multitudinaria manifestación y continuada más tarde durante semanas con la regularidad de un rito- a la desigualdad que la sociedad chilena padecería. Los hechos de octubre serían, pues, el resultado de una sociedad con profundos problemas de justicia distributiva, una sociedad que en vez de corregir la desigualdad la había acentuado en las últimas décadas. Esta explicación produjo incluso alguna conmoción moral. Hubo debates acerca de cuán altas eran las remuneraciones de algunos cargos y quienes los desempeñaban hasta se apresuraron a la rebaja voluntaria. A la identificación de la desigualdad como la causa del fenómeno, la siguió pues una estela de culpa, una moralización de la vida colectiva intensa, pero, como era de esperar, breve. El problema con esa explicación era, sin embargo, que no se condecía con los hechos.

El año 2017, un informe del PNUD (Programa de Naciones Unidas para el Desarrollo) explicaba que la desigualdad en Chile, sea como fuere que se la midiera, había disminuido. Vale la pena reproducir el cuadro que ese informe incluía: 
Cuadro 1. DESIGUALDAD DE INGRESOS 1990 A 2015

\begin{tabular}{lccccc}
\hline & Gini & $\begin{array}{c}\text { Palma } \\
\text { D10/(D4-D1) }\end{array}$ & $\begin{array}{c}\text { Razón quintiles } \\
\text { Q5/O1 }\end{array}$ & $\begin{array}{c}\text { \% pobreza } \\
\text { de ingresos }\end{array}$ & $\begin{array}{c}\text { \% salario } \\
\text { mujer/hombre }\end{array}$ \\
\hline 1990 & 52,1 & 3,58 & 14,8 & 68,0 & 76,9 \\
1996 & 52,2 & 3,61 & 15,2 & 42,1 & 80,9 \\
2000 & 54,9 & 4,17 & 17,5 & 36,0 & 84,8 \\
2003 & 52,8 & 3,72 & 15,3 & 35,4 & 84,6 \\
2006 & 50,4 & 3,25 & 13,3 & 29,1 & 88,0 \\
2009 & 50,0 & 3,16 & 12,8 & 25,3 & 84,3 \\
2011 & 49,1 & 3,01 & 12,2 & 22,4 & 86,4 \\
2013 & 48,8 & 2,96 & 11,6 & 14,4 & 84,6 \\
2015 & 47,6 & 2,78 & 10,8 & 11,7 & 84,4 \\
\hline
\end{tabular}

Fuente: PNUD (2017, 21)

El cuadro muestra, de manera elocuente, que la desigualdad relativa había venido disminuyendo en las últimas décadas.

Otras investigaciones mostraban que si se la medía por cohortes, la desigualdad de ingresos disminuía aún más. Si se comparaban los datos de las encuestas Casen de los años 1992-2003 con la serie entre el año 2000 y 2013, el índice Gini había caído 26 puntos (Sapelli 2016, 48-49). La encuesta Casen mostraba que la pobreza había disminuido en las tres últimas décadas desde casi un $50 \%$ a menos de $10 \%$, y entre los años 2006 y 2017, desde 29,1 a 8,6 (Ministerio de Desarrollo Social y Familia 2019, 14). En fin, otro informe del PNUD, consistente con todos esos datos, situaba a Chile entre los países con alto o muy alto desarrollo humano (PNUD 2019, 344).

Así, entonces, lo que cabía identificar a la base del problema no era la desigualdad, sino más bien la vivencia de la desigualdad. ¿Por qué, a pesar de que parecía haber objetivamente disminuido, se la sentía más lacerante que nunca? ¿A qué se debía, pues, el incremento en la vivencia de la desigualdad? Se sumaba a ello la índole de la protesta. Sin orgánica que la condujera ni programa ideológico que la orientara, a los reclamos reivindicativos se sumaron los grafitis, performances, un rechazo a toda forma de autoridad, cuya víctima transferencial fue el presidente, y otras formas altamente dramáticas de protesta. ¿A qué se 
debía que esa mayor vivencia de la desigualdad — suponiendo que ella fuera también el factor clave - se expresara de esa forma? Dejemos por un momento la respuesta a esas preguntas para detenernos en otro aspecto del debate que estos hechos suscitaron.

En el debate que siguió inmediatamente a los días de octubre o, mejor, en las opiniones que inundaron los medios de comunicación, solió también confundirse la explicación del fenómeno con la adscripción ex post de significados normativos. Como es fácil comprender, una cosa es identificar las razones normativas que hacen correcta o que justifican una determinada acción, y otra cosa, distinta, las causas que condujeron a ella. Una cosa es afirmar que la causa de que Otelo asesinara a Desdémona fueron los celos; otra cosa es afirmar que los celos son una razón que hace correcto el asesinato. Y viceversa. La literatura analítica distingue por eso entre razones justificadoras o normativas y razones explicativas (Dancy 2000). Desde otro punto de vista - que ya insinuaba Marx-, puede distinguirse entre las intenciones de los actores y el análisis del conjunto, cuyos elementos los actores pudieron perfectamente ignorar (Aron 1989, 107).

En el caso de las opiniones que se vertieron esos días, ambos planos se confundieron. Los actores sociales y políticos se apresuraron, como era natural, a adscribir un significado a esos hechos, un significado, desde luego, que coincidiera con su propio punto de vista. Así, por ejemplo, se dijo que uno de los motivos de lo que ocurría era el anhelo de un cambio constitucional. Y desde luego es probable que un cambio constitucional cuente con abundantes razones normativas para justificarlo (aunque analizarlas no es el objetivo de estas líneas), pero eso no las convierte en causa o motivo de la conducta que entonces inundó las calles.

Por supuesto que si la adscripción de razones normativas tiene éxito - esa es una de las medidas del éxito político_-, de ahí en adelante pueden ser eficaces como motivos y la gente explicará retrospectivamente su propio comportamiento echando mano a esas razones.

Pero ahora podamos volver sobre el problema que los datos parecen plantear: ¿por qué, a pesar de que bajo cualquier indicador la desigualdad había disminuido, la vivencia de esta se incrementó?; ¿cómo explicar la particular índole de esa protesta, su cariz a veces dramático, la heterogeneidad de sus mensajes y su carácter poco reivindicativo? 


\section{LA PARADOJA DEL BIENESTAR}

Entre los varios factores que podrían explicar el fenómeno del incremento en la vivencia de la desigualdad, uno de los más iluminadores es el que ha identificado Amartya Sen bajo el concepto de objetividad posicional. El interés de este concepto deriva del hecho de que ayuda a entender lo que pudiera llamarse la paradoja del bienestar, acerca de la cual llamó la atención muy tempranamente, a mediados del siglo XIX, Tocqueville — por la misma época, Marx $(1946,41)$ acuñaba su tesis de la 'ilusión objetiva' (Sohn-Rethel 1978, 196).

Habitualmente pensamos que la objetividad es una cualidad de los juicios cuya validez o valor de verdad es independiente de la posición y características de quien los emite. Pero parece obvio que, para la formación de nuestras creencias y la justificación de acciones, la objetividad es posicionalmente dependiente (Sen 2009, 157). Un grupo de personas puede compartir un puñado de creencias derivadas de su posición, aunque un escrutinio desde varias posiciones (trans-positional assessment) les mostraría que aquellas son erróneas (Sen 1993, 130). Sen ha sugerido entonces que la objetividad posicional es equivalente a lo que Marx llamaba una ilusión objetiva. Un ejemplo — tomado de Sen- permite aclarar ese fenómeno.

Kerala, en la India, tiene la más alta expectativa de vida al nacer (cercana a Europa) y, sin embargo, explica Sen, la percepción de morbilidad es también la más alta. En el extremo opuesto se encuentra Bihar, cuya expectativa de vida al nacer es de las más bajas y sin embargo la percepción de morbilidad es muy baja; ¿cómo puede ocurrir eso? Lo que ocurre, explica el autor, es que la mejora objetiva en la salud contribuye, al mismo tiempo, a un aumento en la conciencia sobre las enfermedades. Y el maltrato de la salud conlleva una inconsciencia acerca de ella (Sen 2009, 164). Una sociedad con mayor bienestar — es el caso de la sociedad chilena cuando se la compara con la situación dos décadas atrás - es también mucho más perceptiva a la desigualdad. La desigualdad no es independiente del incremento del bienestar. Tocqueville, con esa habilidad suya para la imagen elocuente y a la vez sobria, lo dice de manera inmejorable: el yugo es más insoportable mientras más liviano. La misma idea expresa poco más adelante Durkheim $(2012,220)$ en su famoso estudio sobre el suicidio: 


\begin{abstract}
Por mucho que se quiera, para satisfacer los deseos hay que contar con medios; lo que se tiene, determina lo que se quiere tener. Por consiguiente, cuanto menos posea uno, menos intenta ampliar el círculo de sus necesidades. La impotencia nos constriñe a la moderación acostumbrándonos a ella. Además, donde la mediocridad es general, nada viene a excitar el deseo. En cambio la riqueza, por los poderes que confiere, crea la ilusión de que nos engrandecemos por nosotros mismos. Al disminuir la resistencia que oponen las cosas, creemos que podemos vencerlas indefinidamente. Ahora bien, cuanto menos limitado esté uno, más insoportable le parece toda limitación.
\end{abstract}

Pero, como es obvio, la mayor vivencia de la desigualdad no es solo una ilusión objetiva. También hay otros factores que contribuyen a ella.

Entre esos otros factores vale la pena mencionar la forma en que la sociedad chilena, luego de un muy rápido proceso de modernización, legitima las desigualdades. Como es sabido, todas las sociedades poseen grados variables de desigualdad y uno de los rasgos que permiten compararlas es la forma en que logran hacer a esta última aceptable. Pareto $(1987,75)$ mostró tempranamente, a inicios del XX, que todas las sociedades semejan una pirámide, una estrecha cúspide y una amplia base. Por lo general, observó, hay movilidad en los sectores intermedios de la pirámide y la cúspide se mantiene incólume gracias a la cooptación que hace plausible la promesa de movilidad. Como ello no suele ocurrir, exageraba Pareto, la historia parece un cementerio de aristocracias o de elites.

Ahora bien, la modernización capitalista legitima la desigualdad con la expansión creciente del consumo y la promesa meritocrática: la idea de que cada uno tendrá tantos recursos como esfuerzos haga para obtenerlos. Y ocurre que ambas formas de legitimar la desigualdad han fallado. La expansión del consumo y el bienestar se hizo notoriamente más lenta, y la meritocracia no ha logrado contar con estructuras que la hagan plausible. El sistema educacional, que es el dispositivo que, por antonomasia, dota de plausibilidad a la idea meritocrática, no soportó el escrutinio al que se la sometió en los últimos años. De esa manera, el ideal meritocrático más que un principio distributivo se reveló como una fantasía y la herida de la desigualdad quedó al descubierto, sin restañar. 
La sociedad chilena estaría, pues, en parte, atrapada en una de las varias versiones de la paradoja del bienestar.

Lo anterior no agota, desde luego, la descripción del fenómeno. En él puede verse también un fenómeno de desclasificación social que es como Durkheim va a caracterizar una de las dimensiones de la anomia. En términos generales ello equivaldría, como consecuencia del cambio en las condiciones materiales, a una disolución de la conciencia moral compartida.

\section{EL PROBLEMA DE LA ANOMIA}

La palabra anomia designa, en términos generales, una especie de lapsus en la regulación normativa de la conducta. En la obra de Durkheim, quien acuñó el concepto, ese fenómeno puede designar tanto un desorden individual como social (Lockwood 2000, 69). Para aludir a la dimensión social de ese fenómeno, ese autor emplea la expresión 'desclasificación'. Todas las sociedades, sugiere, clasifican las posiciones y las tareas sociales asignándoles una cierta oportunidad de recursos a los que pueden legítimamente aspirar:

en cada momento de la historia hay, en la conciencia moral de las sociedades, una idea imprecisa de lo que valen, respectivamente, los diferentes servicios sociales, de la remuneración relativa que se debe a cada uno de ellos, y, por consiguiente, del nivel de vida que conviene al promedio de los trabajadores de cada profesión. Las diferentes funciones están jerarquizadas en la opinión pública y a cada una se atribuye cierto coeficiente de bienestar, según el lugar que ocupa en la jerarquía. (Durkheim 2012, 216)

Sin embargo, cuando ocurren transformaciones "demasiado súbitas (ya sea por crisis dolorosas o cambios felices)", se produce una desclasificación y sobreviene un tiempo de desorganización inevitable:

Hace falta tiempo para que la conciencia pública reclasifique a los hombres y las cosas. Hasta que las fuerzas sociales liberadas no vuelvan a encontrar su equilibrio, el valor permanece indeterminado $y$, por consiguiente, toda reglamentación será defectuosa durante algún tiempo. Ya no se sabe lo que es posible y lo que no, lo que es 
justo o injusto, qué reivindicaciones y esperanzas son legítimas y cuáles no. Por consiguiente, se aspira a todo. (Durkheim 2012, 219)

No es difícil apreciar en el caso chileno — en la rápida modernización que el país experimentó- un ejemplo de la desclasificación que Durkheim describe.

El fenómeno, especialmente entre los más jóvenes, se acentúa como consecuencia de que los grupos primarios de pertenencia, las habituales y más inmediatas agencias de socialización, la familia, la iglesia, el barrio, se han debilitado como resultado del cambio en las condiciones materiales de la existencia. El desenlace es que las nuevas generaciones se han quedado, por decirlo así, a solas con su subjetividad como una fuente definitiva de certeza. Conviene detenerse en este fenómeno que, en el caso de la cuestión generacional en Chile, es posible observar.

Suele creerse que uno de los rasgos culturales de las sociedades que se modernizan, es la desaparición de las certezas, de los valores que orientan la conducta, y su sustitución en cambio por el relativismo, la idea de que todas las posiciones o puntos de vista son equivalentes. Desgraciadamente, la situación es exactamente la inversa. En procesos de cambio como el que la sociedad chilena experimenta desde hace algún tiempo, no es el relativismo el que aparece, sino el absolutismo de la propia voluntad. Despojado de toda orientación normativa, el individuo termina recurriendo a sí mismo como única fuente de certeza. Carentes de instituciones, los sujetos abrazan lo único que les queda que es su yo, su subjetividad interior, que pasa a transformarse en la única fuente de orientación y de certeza. Entonces, cada uno erige lo que siente en principio de validez general, sin reflexión alguna. Lo anterior se entiende bien cuando se atiende el papel que cumplen las instituciones en la existencia humana.

El individuo es un sujeto indigente en el que, como ha mostrado Arnold Gehlen (1988), no existe el sostén seguro de los instintos. Por el contrario, el ser humano debe soportar la carga de un exceso pulsional y debe continuamente inventarse a sí mismo. Lo peculiar de su condición es que para existir debe 'descargar' ese exceso estabilizándolo en instituciones, pautas de conducta que le ahorran esfuerzo y reducen ese plus (Gehlen 1988, 56). Las instituciones, entonces, modelan y repri- 
men la subjetividad, el exceso pulsional, estabilizando la conducta. Así entendidas, las instituciones no tienen por función regular externamente la conducta, sino que donde ellas existen, y funcionan, la conducta resulta también configurada, por decirlo así, desde dentro. Las formas de experimentar el mundo, los valores que se persiguen, las emociones y las acciones voluntarias son asimismo moldeados por instituciones. Los seres humanos comercian, trabajan, mandan u obedecen, rezan y establecen relaciones afectivas, aunque suene sorprendente, al interior de una institución: el mercado, la familia, el sistema político, la iglesia. Sin instituciones viven en permanente alteración, sin posibilidad alguna de ensimismarse (Ortega y Gassett 2006, 527).

De esta manera, cuando las instituciones se debilitan, cuando la sociedad - en los términos de Durkheim - se desclasifica, aparece lo que puede ser descrito como un brote pulsional, algo que la literatura acerca de revueltas y fenómenos de masas ha descrito desde antiguo.

Pero, como se verá de inmediato, la única forma de describir este tipo de procesos no es la anomia. A contar de los años ochenta hay una amplia literatura que se pregunta cuáles son los factores que en las sociedades contemporáneas desatan la protesta y casi toda ella describe lo que puede ser denominado una especie de contradicción cultural de la que sería muestra el rasgo variopinto de la protesta.

\section{LAS CONTRADICCIONES CULTURALES DE LA MODERNIZACIÓN}

Basta dar un vistazo a las calles de Santiago o haber presenciado incluso a la distancia las manifestaciones, para advertir en ellas dos rasgos que, al observador, hasta desprevenido, saltan a la vista: no hay en ellas ni orgánica que la conduzca, ni programa ideológico que las oriente. En vez, existe una amplia gama de demandas que parecen indicar, más que una demanda reivindicativa - más que indicar algo de lo que se ha sido despojado-, el deseo extendido de configurar el mundo.

¿A qué se debe ese movimiento, por llamarlo así, de intenso deseo de configurar la cultura? Un vistazo a la literatura muestra una notable coincidencia a la hora de diagnosticar ese fenómeno. Toda ella parece constatar una suerte de contradicción en la sociedad moderna entre un mundo que para proveer el bienestar material reclama alta competencia y rigor técnico, y una cultura del consumo que estimula la subjetividad. 
Los habitantes de las sociedades modernas vivirían, así, en medio de una inconsistencia: de una parte, la disciplina rutinaria y la competencia que reclama la producción técnica, y, de otra parte, el anhelo de autoeditarse que el consumo estimula.

Por supuesto, los diversos autores discrepan en los diversos detalles teóricos de ese diagnóstico; sin embargo, todos ellos tienden a coincidir en esa contradicción entre una sociedad que para mantener el bienestar material requiere una alta tecnificación, pero cuya cultura al mismo tiempo estimula el anhelo de autonomía.

Habermas, por ejemplo, observó, a comienzos de la década de 1980, que se estaban desarrollando conflictos en las sociedades occidentales que se desviaban de los patrones tradicionales. Estos nuevos conflictos, agregó, no surgen en el ámbito de la reproducción material, no son canalizados en el sistema de partidos y tampoco se les morigera por compensaciones propias del sistema. En cambio, surgen en las áreas de la reproducción cultural o de la integración social. El problema sería relativo a las 'gramáticas de las formas de vida' y aparecería en las costuras que atan al sistema social, altamente abstracto, con la esfera de significados del mundo de la vida:

Una práctica alternativa se opone a la instrumentalización de las profesiones orientadas al lucro; a la movilidad del trabajo que depende del mercado; a la extensión de la competencia y el rendimiento hacia la escuela. Esa práctica es también dirigida contra el proceso por el cual los servicios, relaciones y tiempo son transformados en valores monetarios, contra la definición consumista de los estilos de vida (...) La disolución siquiera parcial de los roles de empleados y consumidores, de clientes y ciudadanos, debería, de acuerdo con las concepciones de algunos teóricos, abrir el camino para contrainstituciones desarrolladas desde el interior del mundo de la vida para limitar así la dinámica del sistema económico y administrativo. (Habermas 1981, 36-37)

Esa lucha por la gramática de las formas de vida, como la denominó este autor, permitiría comprender el componente emocional que poseen los nuevos movimientos sociales. La dramatización de la protesta, las performances que transforman a la ciudadanía en una audiencia — fenómenos que en Santiago es posible observar-, no serían solo re- 
cursos estratégicos, sino que expresarían los valores y los elementos no discursivos que subyacen a las culturas emergentes (Flam y King 2005).

Otros autores como Alain Touraine $(1985,1994)$, Daniel Bell (1996 [1976]) o Alberto Melucci (1989), si bien con connotaciones teóricas distintas, llaman la atención hacia el mismo fenómeno. En el centro de la cultura del moderno capitalismo estaría instalada una contradicción, como la llamó Bell, cultural, que se habría manifestado muy tempranamente en el modernismo como movimiento estético, pero que es posible detectar en los mismos inicios de la cultura moderna; la sospecha de que por debajo de un mundo racionalizado y técnico late una realidad que pugna por salir y que lo desmiente. La disponibilidad de recursos de las sociedades que experimentan la modernización invitaría a los individuos a realizar todo su potencial, pero al mismo tiempo comprendería una multiplicidad de organizaciones abstractas que regulan y controlan casi todos los aspectos de la vida de los individuos. Melucci ha descrito por eso a los integrantes de los nuevos movimientos como 'nómades del presente', puesto que sus medios organizacionales y sus prácticas no son medios orientados al mañana sino fines en sí mismos. La observación de Melucci es especialmente significativa cuando se atiende el hecho de que muchos de estos movimientos — salvo por el empleo de una cierta imaginería que Marx advirtió- poseen una obvia desconexión con el pasado, hay en ellos una especie de ruptura en la cadena de la temporalidad.

Jameson (2015), en sus estudios sobre la cultura contemporánea, ha caracterizado lo anterior como una ruptura en la cadena de significantes. Como es sabido, para Sassure (1965) el significado no proviene de una relación entre el significante con la realidad que significa, sino que deriva de la relación de un significante con otros. Cuando esa cadena se rompe, el sentido desaparece. Pues bien, los jóvenes parecen experimentar 'una ruptura de la cadena significante'; no logran hoy unificar el presente, el pasado y el futuro en una misma experiencia. La ruptura de la temporalidad libera al presente de todas las significaciones de que es portador, y así liberado el presente se vuelve intenso, cercano a la "experiencia alucinadora de la euforia" (Jameson 2015, 66).

En la literatura nacional es posible observar diagnósticos semejantes. Martucelli y Araujo (2012) han explorado la forma en que los cambios en la estructura o a nivel del sistema social impactan la bio- 
grafía de los individuos. Esta investigación, inspirada por el principio de imaginación sociológica de Wright Mills $(2000,5)$ o por la sugerencia de Sartre (el análisis social se trata, sugirió este autor, de averiguar lo que el hombre hace con lo que han hecho de él $[1982,989])$, arriba a la conclusión de que la modernización y la aparición de sistemas abstractos se experimenta como una imposición distante que no produce sentido:

cualquiera que sea la fuerza del neoliberalismo en tanto que ideología de los principales actores políticos (y de los grupos dirigentes) ella está muy lejos de definir el contenido efectivo de la conciencia política e histórica de la mayoría de los chilenos. (Martucelli y Araujo 2012, 71)

La investigación de Martucelli y Araujo se inspira en una hipótesis formulada, en el cambio de siglo, por Manuel Antonio Garretón (2000). Este autor, siguiendo las tesis más generales de Touraine, sugiere que en el cambio de siglo se advierte un proceso hasta cierto punto contradictorio en el que se entrelazan la modernización racionalizadora y capitalista, centrada en el modelo de sociedad industrial de Estado nacional, con el surgimiento de pertenencias locales y comunitarias que tienden a exacerbar la subjetividad de las emociones.

En efecto, la cuestión esencial de la modernidad, cual es la constitución de sujetos, sigue vigente, sólo que ello se hace con una expansión de las vertientes expresivas y de memoria colectiva más allá de la vertiente puramente racionalizante de la sociedad industrial de estado nacional. Es decir, en este tipo societal postindustrial globalizado (...) se exacerba la vertiente racionalista, pero también la subjetividad de las pulsiones y emociones y las identidades 'esencialistas' o históricas constitutivas de sujetos. Estamos frente a un tipo societal enteramente 'moderno', donde incluso los elementos adscriptivos, tradicionales o religiosos tienden a desprenderse de su dimensión natural, atávica y metasocial y a constituir sujetos históricos. (Garretón 2000, 44)

Como se observa en este rápido repaso de la literatura, el malestar en las sociedades que se modernizan parece poseer causas que van más allá, o más acá según cómo se mire, de los reclamos normativos que los 
actores políticos les adscriben. Al parecer, hay subyacente en las sociedades que se modernizan, o más ampliamente en la cultura moderna en su conjunto, un cierto malestar - la antigua malaise - , que busca una y otra vez expresarse por los intersticios que la racionalización de la vida va dejando despejados (Yack 1986). Esa malaise no tiene, desde luego, contenido normativo específico, sino una fuente que la alimenta una y otra vez, y le promete curarla: la subjetividad.

¿Qué significado, cabe preguntarse, tiene ese hecho para la comprensión de algunos de los problemas de la sociedad contemporánea? Una rápida mirada a la literatura muestra que la subjetividad puede concebirse de dos formas distintas que alguna relevancia poseen desde el punto de vista político.

De una parte, la subjetividad puede ser vista como una experiencia domeñada por la razón que, a partir de allí, se esfuerza por extenderse a las instituciones. Un punto de vista como este es el que puede colegirse de la obra de autores como Rousseau o Kant. La autonomía, la posibilidad de servirse de la sola razón, individual o colectivamente, fundaría amplios ideales contemporáneos, entre ellos el ideal democrático. Pero, de otra parte, la subjetividad puede ser concebida, como sugerirían Gehlen o Luhmann, como el depósito de un exceso que contradice a las instituciones. Habría, pues, entre la subjetividad y las instituciones, una rivalidad — por llamarla así — insalvable.

Esas dos formas de concebir la subjetividad explican, por supuesto, las dos formas inmediatas y generales de reaccionar frente a la protesta en la sociedad contemporánea: una de ellas ve la protesta como un principio de emancipación; la otra, como una falta de institucionalización.

\section{LA CRISIS DE LEGITIMIDAD Y DE LA REPRESENTACIÓN}

Es probable que todo lo anterior influya en lo que se ha llamado una crisis de legitimidad política, la sensación extendida de que la ciudadanía no se reconoce en sus instituciones.

Las instituciones reposan sobre un elemento mudo: la creencia de que ellas merecen, por algún motivo, ser obedecidas. En las democracias contemporáneas, las fuentes de la legitimidad (aquello que proveía motivos para obedecer) fueron tradicionalmente dos (Rosanvallon 2011). Por una parte, el procedimiento electoral a la hora de asignar las 
posiciones de poder en el Estado y, por la otra, la capacidad del Estado para prestar servicios a las personas. Y ocurre que ambas fuentes de legitimidad se han debilitado.

El procedimiento electoral que confiere el poder a las mayorías tiene el problema de que las mayorías ya no existen. O, mejor aún: hoy existe una multitud de minorías, cada una portando o reclamando intereses específicos. La vieja imagen del electorado, que reflejaba las distintas posiciones en la estructura social —el proletariado, la izquierda; la burguesía, la derecha; la mesocracia, un centro que servía de eje-, ha sido sustituida por la de una ciudadanía que se expande en múltiples direcciones e identidades. Y, así, el clivaje ha pasado a ser puramente político.

Habitualmente, las divisiones al interior del sistema político se atribuyen a factores sociológicos, como la división en clases sociales (Lipset y Rokkan 1967). Así, solía decirse, la izquierda tenía a sus votantes en la clase popular y la derecha en la más acomodada. La modernización, la expansión del consumo, el acceso a bienes estatutarios hace, sin embargo, que las personas ya no se definan por la clase o el estatus atribuido, sino que sientan que su posición es más o menos flotante, electiva. Es la identidad predominante de esos grupos medios (que no coincide, como es obvio, con la vieja clase media) lo que explica que los factores que permiten predecir sus grandes líneas hayan cambiado: ya no es la clase, sino el estatus, incluso fugaz, adquirido por el consumo, el temor a la pérdida de la mejora material, lo que define las preferencias. En la historia política reciente de Chile, ese clivaje puramente político se inauguró con la oposición entre autoritarismo y democracia hace tres décadas. Y buena parte de la evolución política descansó en la eficacia simbólica de esa oposición. Una vez que esa eficacia se perdió, no fue el viejo clivaje sociológico el que renació, sino que fue sustituido por otro dependiente de las preferencias más bien líquidas de los nuevos grupos medios como parecieron sugerirlo los resultados electorales.

Así, el proceso electoral, una tradicional fuente de legitimidad en las democracias modernas, dejó de expresar a las mayorías. Mejor aún, las mayorías dejaron de ser estables, y en vez de estar en consonancia con las posiciones en la estructura social, pasaron a ser cambiantes al compás de los anhelos de bienes inmediatos. 
Por otra parte, el Estado concebido ya no como poder político, sino ahora como administración destinada a atender necesidades de los sujetos, también se ha debilitado. Ha contribuido a ello no solo la expansión del mercado, sino además el hecho de que las necesidades de los individuos son menos estandarizadas. Mientras en el capitalismo inicial (el de Chile avanzado el siglo XX) había necesidades de clase — por llamarlas de alguna forma-, hoy las necesidades son más diferenciadas. Hay, por supuesto, necesidades uniformes que han sido desatendidas, pero junto con las identidades múltiples han surgido demandas también múltiples para las cuales la administración estatal es obviamente incapaz.

Todo lo anterior configura un contexto político favorable a la protesta. Puede haber rabia acumulada, líderes carismáticos y otros recursos similares, pero si no existe un entorno político favorable, el movimiento y la protesta o no despierta o no tendrá destino alguno. El entorno o medio ambiente político explicaría la aparición de este tipo de movimientos al igual que la existencia de una retórica, de un conjunto de significados socialmente eficaces que crean un marco cognitivo favorable al cambio. Esos marcos favorables a la acción colectiva proveerían un diagnóstico acerca de lo que ocurrirá dado el estado de cosas que se trata de cambiar, formulan un plan de acción para evitarlo y proveen motivos para llevarlo adelante (Snow et al. 1986).

Esto, desde luego, ha estado presente en el caso de Chile.

\section{LOS DESAFÍOS DEL FUTURO: EL LUGAR DE LA MERITOCRACIA}

Todos los factores que en términos generales se han descrito parecen coincidir en una cosa. Las sociedades que se modernizan, que cambian de manera rápida las condiciones materiales de la existencia de sus miembros y mejoran su bienestar, experimentan inevitablemente un desajuste entre la estructura y la subjetividad. Ese desajuste, hemos visto, puede ser descrito de múltiples formas, desde la anomia a las contradicciones entre la racionalización técnica y el mundo de la vida.

Pero, como es obvio, ese tipo de explicaciones no permite juzgar el contenido normativo de la protesta. Según observamos al comienzo, es imprescindible distinguir entre los motivos de una acción o, si se prefiere usar este término, las causas de una conducta social y las razones que sus partícipes esgrimen, ex post, para hacerla legítima o correcta. A 
esa distinción la precede otra. Una cosa es narrar o describir lo que ocurre - los hechos violentos en el Metro, la multitudinaria concentración que le siguió, la destrucción cotidiana, etcétera-y otra cosa es conferirles inteligibilidad. $\mathrm{Y}$ esta última puede alcanzarse echando mano a los factores estructurales que pudieron provocar esos hechos (que es lo que hemos intentado, en términos generales, en lo que antecede) o recurriendo a la intención o propósito de los actores.

Es hora de referirse a este último aspecto: ¿qué es lo que subyace en los reclamos normativos de los días que siguieron a octubre? En el conocido prólogo de su Filosofía del derecho, Hegel asigna como tarea a la filosofía descubrir la "rosa en la cruz del presente" (Hegel 1991, 22). Es la tarea de la reconciliación que cabe a la filosofía (Peña 2017). Reconciliar a los ciudadanos con sus instituciones no es, sin embargo, una tarea puramente conservadora, puesto que en toda sociedad hay un potencial normativo que pugna por salir, y corresponde a la tarea intelectual y a la política identificarla. Al hacerlo, la política adquiere esa 'sombría grandeza' - la expresión es de Aron $(1993,395)$ — que la aleja tanto de las simples ensoñaciones conceptuales como del rampante apego a los simples hechos.

Ahora bien, ¿cuál es el componente normativo que subyace a la sociedad chilena, la fuente de sus aspiraciones y de la frustración que se expresa en los reclamos de octubre? La sociedad chilena ha experimentado en apenas una generación cambios en sus condiciones materiales de existencia que antes tomaban dos o tres. Quienes anteayer eran proletarios, han accedido al consumo y a la movilidad intergeneracional. $\mathrm{Y}$ es inevitable que ahora atribuyan a sí mismos, a su esfuerzo y a su propio quehacer, el mayor bienestar de que disponen. Así queda plantada la semilla de la meritocracia, el ideal según el cual los recursos y oportunidades se distribuyan en proporción al esfuerzo que se hace para obtenerlos. Es difícil exagerar la importancia de ese fenómeno. Y es que la meritocracia no es un mero principio distributivo; es también un criterio para organizar la propia biografía. Los cambios estructurales se expresan en la forma en que los individuos reconstruyen sus trayectorias individuales. Así, una vez que ese principio se instala en la cultura, las personas comienzan a organizar su memoria, a reconstruir su peripecia vital y la de quienes tienen cerca como el fruto de su esfuerzo. 
La meritocracia, a contar de ahí, es el combustible del esfuerzo personal, pero también es su amenaza. Basta recordar la distopía de Michael Young (1958) para imaginar lo que ocurriría a una sociedad totalmente meritocrática. Muy pronto en ella las posiciones sociales desventajadas serían muestra del fracaso personal, y cada uno de quienes quedasen por atrás en la carrera invisible del prestigio y del poder pasarían a formar parte de un estrato inferior, cuya dignidad acabaría siendo estropeada. Así, muy luego el principio del esfuerzo o el talento como criterio distributivo sería sustituido por la simple adscripción, y entonces la condición tal o cual — derivada del género, la etnia o cualquier otra característica no consentida - principiaría a ser reclamada como título para obtener oportunidades o ventajas sociales.

Lo que enseña esa distopía es que las sociedades en que se expande el ideal meritocrático necesitan, al mismo tiempo, contar con mecanismos que permitan distribuir el riesgo del fracaso. La vida humana es una rara mezcla de destino y desempeño, de esfuerzos personales y dotaciones recibidas, de transpiración y de misteriosas oportunidades. La literatura denomina suerte moral a esa extraña condición humana (Williams 2012; Nagel 1979). Si bien sabemos que lo que nos ocurre se debe en parte importante a factores que no manejamos —el talento que cada uno posee, la oportunidad que tocó alguna vez inesperada a su puerta-, igualmente pensamos la vida humana y la propia trayectoria como si fuera el resultado de un designio personal. El principio meritocrático coexiste así con la suerte moral.

Pero como sabemos que lo que cada uno es o ha llegado a ser es fruto, siquiera en parte, de la suerte moral, las sociedades deben corregir el principio meritocrático mediante una distribución igualitaria del riesgo, de manera que la sombra del fracaso no amenace los bienes básicos - salud o educación - que hacen de la vida una invitación al desafío personal. Si la vigencia única del principio meritocrático amenaza la igual dignidad, categorizando a las personas en atención al resultado de su vida, una distribución que prescinde del esfuerzo deteriora también la dignidad y el sentido del propio valor. De este modo, la meritocracia como ideal normativo — sembrado por la modernización capitalista - afronta el desafío de equilibrar, por decirlo así, desempeño y destino.

En la imaginería de la política contemporánea suelen resonar las palabras de Marx quien, en su Crítica al programa de Gotha 
(2000 [1875], 615), dijo que la sociedad escribiría alguna vez en sus banderas: de cada cual según su capacidad, a cada cual según su necesidad. Esa divisa, sin embargo, podría inspirar la distribución si las necesidades fueran independientes de la agencia humana, pero la sociedad contemporánea, el moderno capitalismo, enseña que no es así. Si algo enseña la modernización capitalista, para quien ha asistido a ella, es que las necesidades humanas se diversifican con el bienestar y que, como advirtió Alfred Marshall en sus Principios de economía, un texto escrito poco después de El capital, el anhelo de diferenciarse era "la más poderosa de las pasiones humanas" $(1997,87)$.

El resultado de todo eso es que la modernización - especialmente en la modalidad capitalista que Chile ha experimentado - promete bienestar, la mejora en las condiciones materiales de la existencia. Sin embargo, a la vez enseña que las sociedades, como decía el Dr. Johnson en sus conversaciones con Boswell, progresan no de satisfacción en satisfacción, sino de deseo en deseo. Y por eso el progreso se teje con hilos de desilusión (Aron 1968b).

\section{CONCLUSIONES}

Los acontecimientos del 18 de octubre no constituyeron un movimiento propiamente reivindicativo, ni una movilización social con orgánica u orientación ideológica. Basta ver las huellas que han quedado en las calles para advertir que en él se reúnen reclamos culturales, algunas formas de anomia y una creciente vivencia de la desigualdad en torno a la cual se arremolinan demandas más tradicionales de bienestar material. Se trata, pues, de un fenómeno provocado por una multitud de factores que - detectados una y otra vez en la literatura - aparecen en procesos rápidos de modernización. Los más relevantes de ellos son el incremento en la vivencia de la desigualdad que es, paradójicamente, un fruto del mayor bienestar relativo (como lo exponen desde Tocqueville a Sen); la anomia, que es resultado de lo que Durkheim llama 'desclasificación social' (y la literatura posterior, un desajuste entre la estructura y las expectativas); el deterioro de los grupos primarios de pertenencia que dejan al individuo a solas con su subjetividad como única fuente de certeza (según advirtió Gehlen); una crisis de legitimidad y representación como consecuencia del cambio de clivaje de la política; y, especialmen- 
te, una contradicción entre las exigencias racionalizadoras que exige la producción del bienestar y la extrema subjetivación de la vida (como, vimos, subrayan desde Habermas a Melucci).

Ese conjunto de fenómenos plantean particulares desafíos a la política en Chile. Junto con atender las reivindicaciones más urgentes - vinculadas con el riesgo de la vejez y la enfermedad, los grandes temores de los grupos medios - habrá que hacer frente a procesos culturales que riñen, inevitablemente, con las instituciones. Desde el punto de vista normativo, la política futura habrá de compatibilizar una razonable distribución del riesgo — las infalibles flechas del destino, la vejez y la muerte - con un estímulo del esfuerzo personal que demanda la cultura meritocrática, uno de los resultados culturales de la modernización capitalista.

Pero no habrá revolución. La revolución supone el cambio de un orden por otro que resulta destruido; la aparición, pues, de un orden nuevo, una ruptura que divide el tiempo en dos. Nada de eso ocurrirá en una cultura que, como advirtió Jameson (2015), tiende a vivir en un presente liberado de todo vínculo con la temporalidad. Habrá por supuesto retórica revolucionaria (¿qué época no ha tenido la suya?), pero la revolución no aparecerá por parte alguna. En cambio se recuperará esa tensión que advirtió Mannheim entre una fuerza retentiva o ideológica, y otra progresiva, o utópica, que caracteriza la cultura de todas las sociedades modernas (Mannheim 2015).

\section{BIBLIOGRAFÍA}

Aron, R. 1968a. La Revolution Introuvable. Reflexions sur les evenements de Mai. Paris: Fayard.

Aron, R. 1968b. Progress and Disillusion: The Dialectics of Modern Society. London: Pall Mall.

Aron, R. 1989. Relato, análisis, interpretación, explicación: crítica de algunos problemas del conocimiento histórico (87-141). En Aron, R., Estudios sociológicos. Madrid: Espasa-Calpe.

Aron, R. 1993. La querelle du machiavélisme (383-395). En Aron, R., Machiavel et les tyrannies modernes. Paris: Éditions du Fallois.

Bell, D. 1996 [1976]. The Cultural Contradictions of Capitalism. New York: Basic Books. [Reedición con un importante post scriptum.]

Dancy, J. 2000. Practical Reality. Oxford: Clarendon Press. 
Durkheim, E. 2012. El suicidio. Madrid: Akal.

Flam, H. y King, D. (eds.). 2005. Emotions and Social Movements. London/New York: Routledge.

Garretón, M.A. 2000. La sociedad en que vivi(re)mos. Introducción sociológica al cambio de siglo. Santiago: Lom, Colección Escafandra.

Gehlen, A. 1988. The Man. His Nature and Place in the World. New York: Columbia University Press.

Habermas, J. 1981. New Social Movements. Telos 49, 33-37.

Hegel, F. 1991. Elements of the Philosophy of Right. Edited by A. Wood. Cambridge: Cambridge University Press.

Jameson, F. 2015. El posmodernismo o la lógica cultural del capitalismo avanzado. Barcelona: Paidós.

Lipset, S.M. y Rokkan, S. 1967. Party Systems and Voter Alignments. New York: Free Press.

Lockwood, D. 2000. Solidarity and Schism. Oxford: Oxford University Press.

Mannheim, K. 2015. Ideology and Utopia. An Introduction to the Sociology of Knowledge. Eastford, CO: Martino Fine Books.

Martucelli, D. y Araujo, K. 2012. Desafios comunes. Retratos de la sociedad chilena y sus individuos. Santiago: Lom.

Marshall, A. 1997. Principles of Economics. New York: Prometheus Books.

Marx, K. 1946. El capital. Crítica de la economía política. Tomo I. México DF: Fondo de Cultura Económica.

Marx, K. 2000 [1875]. Critique of the Gotha Programme (610-616). En McLellan, D. (ed.), Selected Writings. Oxford: Oxford University Press.

Melucci, A. 1980. The New Social Movements: A Theoretical Approach. Theory and Methods/Théorie and Méthodes 19(2), 199-226.

Melucci, A. 1989. Nomads of the Present: Social Movements and Individual Needs in Contemporary Society. Philadelphia: Temple University Press.

Mills, W. 2000. The Sociological Imagination. Oxford: Oxford University Press.

Ministerio de Desarrollo Social y Familia 2019. Desarrollo social 2019. Santiago: Ministerio de Desarrollo Social y Familia.

Nagel, T. 1979. Mortal Questions. New York: Cambridge.

Ortega y Gasset, J. 2006. Ensimismamiento y alteración (527-601). Obras completas. Tomo V. Madrid: Taurus.

Pareto, W. 1987. Los sistemas socialistas (65-142). Escritos sociológicos. Madrid: Alianza.

Peña, C. 2017. Rawls, entre Kant y Hegel. Revista de Filosofía 73, 219-229.

Peña, C. 2020. Pensar el malestar. Sobre la crisis de octubre y la cuestión constitucional. Santiago: Taurus.

PNUD 2017. Desiguales. Orígenes, cambios y desafios de la brecha social en Chile. Santiago: Uqbar. 
PNUD 2019. Informe sobre Desarrollo Humano 2019. Más allá del ingreso, más allá de los promedios, más allá del presente: desigualdades del desarrollo humano en el siglo XXI. Nueva York: PNUD.

Rosanvallon, P. 2011. Democratic Legitimacy. Impartiality, Reflexivity, Proximity. Princeton and Oxford: Princeton University Press.

Sapelli, C. 2016. Chile: ¿más equitativo? Una mirada a la dinámica social del Chile de ayer, hoy y mañana. Santiago: Ediciones UC.

Sassure, F. 1965. Curso de lingüística general. Buenos Aires: Losada.

Sartre, J.P. 1982. Crítica de la razón dialéctica (911-1366). Obras completas. Tomo III. Madrid: Aguilar.

Sen, A. 1993. Positional Objectivity. Philosophy and Public Affairs 22(2), 126-145.

Sen, A. 2009. Idea of Justice. Cambridge, MA: Harvard University Press.

Snow, D., Burke Rochford Jr., E., Worden, S.K. y Benford, R.D. 1986. Frame Alignment Processes. Micromobilization, and Movement Participation. American Sociological Review 51(4), 464-481.

Sohn-Rethel, A. 1978. Intellectual and Manual Labor. A Critique of Epistemology. London: Macmillan Press

Touraine, A. 1985. An Introduction to the Study of Social Movements. Social Research 52(4), 749-787.

Touraine, A. 1994. Crítica de la modernidad. México DF: Fondo de Cultura Económica.

Yack, B. 1986. The Longing for Total Revolution. Philosophic Sources of Social Discontent from Rousseau to Marx and Nietzsche. Princeton: Princeton University Press.

Young, M. 1958. The Rise of the Meritocracy 1870-2033: An Essay on Education and Society. London: Thames and Hudson.

Wagner, P. 1994. Sociology of Modernity. Liberty and Discipline. London, New York: Routledge.

Williams, B. 2012. Moral Luck. Philosophical Papers. Cambridge: Cambridge University Press. EP 